\title{
Development and evaluation of a specialized task taxonomy for spatial planning - A map literacy experiment with topographic maps
}

\author{
Victoria Rautenbach $^{\mathrm{a}, 1}$, Serena Coetzee ${ }^{\mathrm{a}}, \mathrm{A}$. Çöltekin ${ }^{\mathrm{b}}$ \\ ${ }^{a}$ Centre for Geoinformation Science, Department of Geography, Geoinformatics and Meteorology, University of Pretoria, \\ Pretoria, South Africa, victoria.rautenbach@up.ac.za, serena.coetzee@up.ac.za \\ ${ }^{\mathrm{b}}$ GIScience Center, Department of Geography, University of Zurich, CH-8057, Zurich, Switzerland - arzu@geo.uzh.ch
}

\begin{abstract}
Topographic maps are among the most commonly used map types, however, their complex and information-rich designs depicting natural, human-made and cultural features make them difficult to read. Regardless of their complexity, spatial planners make extensive use of topographic maps in their work. On the other hand, various studies suggest that map literacy among the development planning professionals in South Africa is not very high. The widespread use of topographic maps combined with the low levels of map literacy presents challenges for effective development planning. In this paper we address some of these challenges by developing a specialized task taxonomy based on systematically assessed map literacy levels; and conducting an empirical experiment with topographic maps to evaluate our task taxonomy. In such empirical studies if non-realistic tasks are used, the results of map literacy tests may be skewed. Furthermore, experience and familiarity with the studied map type play a role in map literacy. There is thus a need to develop map literacy tests aimed at planners specifically. We developed a taxonomy of realistic map reading tasks typically executed during the planning process. The taxonomy defines six levels tasks of increasing difficulty and complexity, ranging from recognising symbols to extracting knowledge. We hypothesized that competence in the first four levels indicates functional map literacy. In this paper, we present results from an empirical experiment with 49 map literate participants solving a subset of tasks from the first four levels of the taxonomy with a topographic map. Our findings suggest that the proposed taxonomy is a good reference for evaluating topographic map literacy. Participants solved the tasks on all four levels as expected and we therefore conclude that the experiment based on the first four levels of the taxonomy successfully determined the functional map literacy of the participants. We plan to continue the study for the remaining levels, repeat the experiments with a group of map illiterate participants to confirm that the taxonomy can also be used to determine map illiteracy.
\end{abstract}

Keywords: topographic maps, map literacy, map reading, task taxonomy

\footnotetext{
${ }^{1}$ Corresponding author: Email: victoria.rautenbach@up.ac.za, Tel: +27 12420 3489, Address: Centre for Geoinformation Science, Geography building, University of Pretoria, Pretoria, South Africa, 0028
} 


\section{Introduction}

Topographic maps do not only depict relief, but also natural, human-made and cultural features and provide an accurate and comprehensive graphic record of locations. Topographic maps are used extensively, for example, by soldiers for battle planning, by engineers when designing and planning roads, by geologists and surveyors for fieldwork planning and by spatial planners when developing plans for cities or regions (Innes, 1998). Due to the graphically rich nature of topographic maps, they are considered difficult to read and understand (Chang et al., 1985). The abundance of symbols and colours used in topographic maps could be challenging, however, a comprehensive, well-designed legend can assist. According to Chang et al. (1985), the ability to form a 3D mental image of the terrain is considered to be the most challenging aspect when working with topographic maps. The map-reader needs to either interpret contour lines or deduce heights from spot heights.

Map reading is taught in school in many countries, specifically in primary and secondary education (Board, 1981). However, map reading is a complex task (Rayner, 1996; Board, 1981). In fact, Rayner (1996) reviewed various studies and concluded that most adults are map illiterate and unable to complete basic map use tasks. More recently, many more empirical studies highlighted the complexity of map reading tasks; even perceptual tasks that require no expertise, such as size of the symbols or colour discrimination, can hinder map reading severely (Clarke, 2003; Kent and Cheng, 2008; Bryhctova and Coltekin 2014, 2015 and 2016. Ooms et al. (2016) raised the question whether the increased accessibility of maps with the introduction of new technology and tools, such as Google Maps, has affected map literacy of individuals. They found that secondary education pupils (between the age of 11 and 18 years) were able to mostly successfully complete various map reading tasks at different levels of difficulty. This was especially true for older pupils and those currently enrolled for geography. However, the Ordnance Survey (2015) carried out a survey asking 2000 individuals which traditional skills they thought were in danger of dying out, and map reading was in the top spot. The reason provided was the increased reliance on technology, such as GPSs (Ordnance Survey, 2015; Bachmann, 2015). Bachmann (2015) suggests introducing activities into curricula that would alter a student's perception that GPSs and maps are perfect representations of the world. While it might be difficult for many people, map reading is necessary for many everyday tasks as well as professional use, e.g., topographic maps contain essential information for spatial planning and decision-making. Planners formulate plans for optimal land management and development in cities and wider regions. For this they rely on topographic maps (among various other data sources): from gathering information to communicating planned developments. Thus, map literacy is an essential skill for planning professionals. Surprisingly, however, Engel (2004) and Clarke (2007) found that map literacy levels among those involved in development planning in South Africa were simply inadequate. This mismatch naturally presents challenges for effective development planning and indicates a need for reforming the university curricula for educating planners and others who might conduct spatial analysis tasks related to planning. 
Board and Taylor (1977) suggested that map reading experiments for adults rarely used 'realistic' map reading tasks, and that this might skew the results. It also appears that experience plays a major role in reading topographic maps, as experienced individuals are more efficient and effective in interpreting contours and visualization of terrain, among other spatial tasks (Kent and Cheng, 2008; Rinner and Ferber, 2005; Chang et al., 1985). A strong correlation has been reported between self-reported familiarity and experience with topographic maps and participants' performance with them in map reading tasks (Chang et al., 1985).

Map literacy tests designed specifically for planners simply do not appear to exist. Such tests could be used to evaluate map literacy and to initiate remedial actions, where necessary. In this article, we propose a map reading task taxonomy that is specifically relevant for the spatial planning domain. The map reading tasks in the taxonomy were derived from the tasks that are generally used in the planning process. Furthermore, we present results from a user experiment where map literate participants used a subset of the tasks in the proposed taxonomy, and we measured their map reading performance. We worked with map literate participants as a validation mechanism (i.e. we expected them to be successful with the tasks we prepared), and we chose a topographic map for the experiment, as topographic maps are commonly used by planners to gain a general overview of the environment, including terrain. The remainder of the paper is structured as follows: Section 2 presents the map reading task taxonomy; in Section 3 the study design is described; results are presented in Section 4; and in Section 5 the results are discussed and conclusions are provided.

\section{Map reading task taxonomy for planning}

Various researchers have identified and proposed map reading tasks for the evaluation of map literacy. For example, in 1990, Saku (1990) identified the following tasks involved in map reading: reading, analysing and interpreting geographic data. These tasks were extended by Keates (1996), as he justifiably discriminates between identifying and interpreting map symbols: the symbol has to be identified initially, only thereafter interpreted, and lastly, inferred if possible. This concept of tasks that build on each other from basic to advanced was also used by Clarke (2007) to define three map literacy skill levels for the evaluation of functional map literacy: read and understand a single symbol, do simple estimations (entry level); recognise symbol groups, analyse spatial patterns, more complex estimations (level 1); and understanding meaning and inferential reasoning of map phenomena (level 2). Clarke defined 18 map-use tasks and determined the map literacy level required for each task. Based on experimental results, Clarke argued that a person is 'functionally map literate' if the individual is proficient up to level 1. However, professionals working in the development planning environment should preferably be competent up to level 2 (Clarke, 2007; Rautenbach et al., 2014).

Developing an instrument to evaluate map literacy is not a new concept (Koç and Demìr, 2014), however to our knowledge, there is currently no instrument specifically designed for planning 
professionals. To develop our map reading task taxonomy for planners, we considered expert knowledge, peer-reviewed publications, and a number of additional resources, such as national reports and policy documents, and synthesized them (i.e., Board 1978; Morrison 1978; Clarke 2003; Clarke 2007; Engel 2004; Ordnance Survey 2014; Ordnance Survey 1992; Department of Basic Education 2011; Department of Education 2008; Department of Basic Education 2012; Innes 2005; Bolstad 2012; Bayram 2007; Wiegand 2006; Department of the Army 2001; Australian Government 2005; Land Information New Zealand 2009; Innes 2003; Rayner 1996; Board 1981; Saku 1990; Keates 1996). In the proposed taxonomy, we considered tasks for topographic maps, aerial photography and 2D maps (i.e., standard cartographic maps or thematic maps) as alternatives. However, in this study, we report results from an experiment that featured only a single topographic map, as the main idea was to test the taxonomy itself, and not make a map-type comparison.

The proposed taxonomy defines six levels of map reading tasks with increasing difficulty and complexity, ranging from recognising symbols to extracting knowledge (see Table 1). Level 1 to Level 4 (recognise symbology, orientate, locate, and measure or estimate) is considered to be the minimum for functional map literacy. These tasks (Level 1 to Level 4) form the basic building blocks for more advanced tasks. For example, during the first phases of planning (understanding the current environment), a planner/designer needs to extract knowledge from maps (e.g., spatial patterns or relationships between phenomena). For this, planners need to perform basic map reading tasks: recognise symbology on maps, orientate themselves on the map, locate features and estimate distances, etc. on the map.

Table 1. Taxonomy designed specifically for spatial planning related map reading tasks (items we used in our user experiment are highlighted in grey)

\begin{tabular}{|c|c|}
\hline Description & Map task \\
\hline \multirow{4}{*}{$\begin{array}{l}\text { Level 1*: } \\
\text { Recognise } \\
\text { symbology }\end{array}$} & 1.1. Name the phenomenon represented by the symbol \\
\hline & $\begin{array}{l}\text { 1.2. Describe the difference in characteristics of phenomenon based on the symbols or } \\
\text { patterns }\end{array}$ \\
\hline & 1.3. Recognise various topographic features in the area based on symbology or patterns \\
\hline & 1.4. Locate features in different perspectives \\
\hline \multirow{2}{*}{$\begin{array}{l}\text { Level } 2^{*}: \\
\text { Orientate }\end{array}$} & 2.1. Determine direction or bearing \\
\hline & 2.2. Recognise different perspectives \\
\hline \multirow{3}{*}{$\begin{array}{l}\text { Level 3*: } \\
\text { Locate }\end{array}$} & 3.1. Locate a feature \\
\hline & 3.2. Determine the position at a specific point \\
\hline & 3.3. Locate features that exhibit a specific relationship to another feature \\
\hline \multirow{4}{*}{$\begin{array}{l}\text { Level } 4 * \text { : } \\
\text { Measure or } \\
\text { estimate }\end{array}$} & 4.1. Estimate certain topographic elements, for example line of sight \\
\hline & 4.2. Determine the distance between two points or length of a linear feature \\
\hline & 4.3. Determine the area or extent of a region \\
\hline & 4.4. Estimate altitude/height/volume of a specific feature \\
\hline \multirow{3}{*}{$\begin{array}{l}\text { Level } 5 \text { : } \\
\text { Calculate or } \\
\text { explain }\end{array}$} & 5.1. Calculate certain topographic elements \\
\hline & 5.2. Produce and reproduce features \\
\hline & 5.3. Explain patterns of occurrence or features \\
\hline Level 6: & 6.1. Perform a spatial analysis \\
\hline
\end{tabular}


${ }^{*}$ Functional map literacy (Level1 to Level 4)

The proposed taxonomy attempts to update previous map reading tasks that focussed on mainly paper maps. For example, Morrison (1978) listed unfolding as a map reading task. The map reading tasks identified by Board (1978) and Morrison (1978) were mainly a list of actions with little explanation that are applicable to various field and applications. Innes (2003) developed a system for school learners based on the South African Department of Educations (2011) geography syllabus. This system is based on the concept of a hierarchy of tasks that would ultimately contribute to a desired outcome. Innes' $(2005 ; 2003)$ was basic as it is aimed at high school learners and very board. The abovementioned literature formed the starting point of the taxonomy that was developed by combining various resources to condense the information and verify that all possible tasks are included. Most taxonomies or map reading tasks list only focus on functional map literacy, the proposed taxonomy includes complex tasks, specifically aimed towards spatial planning.

A map reading task taxonomy, specifically relevant for the spatial planning domain, is not only useful for testing individuals' map literacy, but could also assist in guiding the development of a curriculum or a course for planning students at university level. The taxonomy could be used as a reference to ensure that students are taught the necessary map reading skills.

\section{Study design}

\subsection{Overview}

To investigate whether the proposed map reading task taxonomy can be used to evaluate functional map literacy, we designed a user experiment with topographic maps, using a subset of the proposed map reading task taxonomy from Level 1 to Level 4 (refer to Table 1). For this study, we recruited participants that we expected to be functionally map literate, and should perform well when asked to complete various tasks from the proposed taxonomy, especially with the topographic map. A subset of the taxonomy was used (the subset is indicated in grey in Table 1). We designed a within-subject experiment; meaning that all participants solved all tasks. We presented 22 questions in a randomized order to minimise and distribute the learning effect (Table 2). Table 2 lists the questions presented to the participants and shows how the questions relate to the tasks specified in our proposed task taxonomy. Most tasks from Level 1 to Level 4 were included in the experiment. As indicated in Table 1, tasks 1.4, 2.2 and 4.4 were excluded: Tasks 1.4 and 2.2 deal with perspective, which is not applicable to topographic maps as they are typically produced from a single perspective. Task 4.4 was excluded, because it would require altitude or height estimations that would not be sensible on a topographic map with contours that already provide altitude information, and similarly, object heights or volumes would be difficult to estimate given the scale and level of abstraction of a topographic map. The format of the survey further limited the tasks that could be 
included. This specifically related to the type of task, for example, participants did not have access to any resources or tools (e.g., a calculator or the Internet), therefore the questions that would require advanced arithmetic (tasks relating to Level 5, Table 1), and tasks involving inference (refer to Level 6, Table 1) were not included. Tasks from Level 5 and Level 6 are better suited for an interview or peer-analytical setting to gather additional information beyond the extent of a survey.

Therefore, our independent variables were the 10 tasks as shown in Table 2, which increase in complexity from one level to the next. Participants solved the questions using a single topographic map (see Section 3.2). We measured the following dependent variables in the experiment: accuracy (also known as effectiveness; was the answer correct?), completion time (also known as efficiency; time taken to complete the question, or response time), and the participants' confidence in their accuracy (does the participant think the answer is correct?). In the taxonomy, task complexity increases from Level 1 to Level 4, and tasks in each level depend on the skills required for tasks in the previous level. Thus, we can expect the participants' accuracy in solving the tasks, their completion time (time taken to complete the question), and confidence (does the participant think the answer is correct?) will decrease from Level 1 to Level 4.

Table 2. Relationship between the experimental questions and the task taxonomy

\begin{tabular}{|c|c|c|c|}
\hline Qn & Experiment question text & Task (refer to Table 1) & Level \\
\hline 1 & \multirow{2}{*}{$\begin{array}{l}\text { Name the feature represented inside the red } \\
\text { circle (area feature) }\end{array}$} & \multirow{2}{*}{$\begin{array}{l}\text { 1.1. Name the phenomenon represented } \\
\text { by the symbol }\end{array}$} & \multirow{6}{*}{ 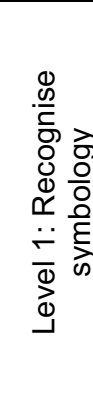 } \\
\hline 2 & & & \\
\hline 3 & \multirow[b]{2}{*}{ Name the features represented by $A$ and $B$} & \multirow{2}{*}{$\begin{array}{l}\text { 1.2. Describe the difference in } \\
\text { characteristics of phenomenon based on } \\
\text { the symbols or patterns }\end{array}$} & \\
\hline 4 & & & \\
\hline 5 & $\begin{array}{l}\text { Indicate the highest point shown in the map } \\
\text { below (click on the map) }\end{array}$ & \multirow{2}{*}{$\begin{array}{l}\text { 1.3. Recognise various topographic } \\
\text { features in the area based on symbology } \\
\text { or patterns }\end{array}$} & \\
\hline 6 & $\begin{array}{l}\text { Indicate the lowest point shown in the map } \\
\text { below (click on the map) }\end{array}$ & & \\
\hline 7 & \multirow{2}{*}{$\begin{array}{l}\text { What is the relative direction from point } A \text { to } \\
\text { point } B \text { ? }\end{array}$} & \multirow{2}{*}{ 2.1. Determine direction or bearing } & \multirow{2}{*}{ 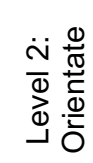 } \\
\hline 8 & & & \\
\hline 9 & $\begin{array}{l}\text { Locate a sewage works (perennial water) - click } \\
\text { in the vicinity of the feature }\end{array}$ & \multirow{6}{*}{$\begin{array}{l}\text { 3.1. Locate a feature } \\
\text { 3.2. Determine the position at a specific } \\
\text { point }\end{array}$} & \multirow{7}{*}{ 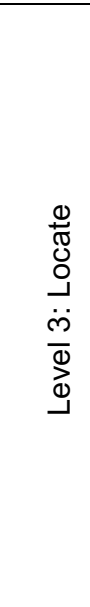 } \\
\hline 10 & $\begin{array}{l}\text { Provide the alphanumeric grid position for } \\
\text { Blockhouse (monument) }\end{array}$ & & \\
\hline 11 & $\begin{array}{l}\text { Provide the coordinate position for the top left } \\
\text { corner of the Barberton Nature reserve }\end{array}$ & & \\
\hline 12 & $\begin{array}{l}\text { Locate a school - click in the vicinity of the } \\
\text { school }\end{array}$ & & \\
\hline 13 & $\begin{array}{l}\text { What is the alphanumeric grid position for } \\
\text { Abbott's Hill? }\end{array}$ & & \\
\hline 14 & $\begin{array}{l}\text { Provide the coordinate position for the Garden of } \\
\text { Remembrance (monument) }\end{array}$ & & \\
\hline 15 & $\begin{array}{l}\text { Locate the power line that crosses through the } \\
\text { Barberton Nature reserve (click on the symbol) }\end{array}$ & $\begin{array}{l}\text { 3.3. Locate features that exhibit a specific } \\
\text { relationship to another feature }\end{array}$ & \\
\hline
\end{tabular}




\begin{tabular}{|c|c|c|c|}
\hline 16 & $\begin{array}{l}\text { Locate a recreation ground that is located along } \\
\text { the railway line (click on the symbol) }\end{array}$ & & \\
\hline 17 & $\begin{array}{l}\text { Is point } A \text { visible from point } B \text { (assuming no } \\
\text { buildings are in the way)? }\end{array}$ & \multirow{2}{*}{$\begin{array}{l}\text { 4.1. Estimate certain topographic } \\
\text { elements }\end{array}$} & \multirow{6}{*}{ 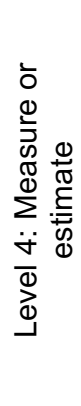 } \\
\hline 18 & In which area, A or B is the slope the steepest? & & \\
\hline 19 & \multirow{2}{*}{$\begin{array}{l}\text { Estimate the straight line distance between the } \\
\text { features indicated (in meters) }\end{array}$} & \multirow{2}{*}{$\begin{array}{l}\text { 4.2. Determine the distance between two } \\
\text { points or length of a linear feature }\end{array}$} & \\
\hline 20 & & & \\
\hline 21 & $\begin{array}{l}\text { Estimate the area of the golf course indicated in } \\
\text { the red block below (in square meters) }\end{array}$ & \multirow{2}{*}{$\begin{array}{l}\text { 4.3. Determine the area or extent of a } \\
\text { region }\end{array}$} & \\
\hline 22 & $\begin{array}{l}\text { Estimate the area of the Barberton Nature } \\
\text { reserve (in square meters) }\end{array}$ & & \\
\hline
\end{tabular}

\subsection{Materials}

A South African topographic map (Figure 1) from the standard South African 1:50 000 raster map series produced by the Chief Directorate: National Geo-spatial Information (CD:NGI) was used in the experiment. CD:NGI is mandated to collect the data and publish the 1:50 000 topographical map series (1 913 sheets) covering the entire South Africa (National Geo-Spatial Information, 2013). Using various symbols and colours, the 1:50 000 topographic map series depict the location of natural and human-made (constructed) features, as well as elevation in $20 \mathrm{~m}$ intervals (National GeoSpatial Information, 2013; Innes, 1998). Specifically, we selected the topographic map of Barberton, a small town in the Mpumalanga province, South Africa, as it shows a combination of urban and natural environments, and thus enables us to test the tasks included in the experiment.

The visualization (i.e., the map) was constant for all participants (no changes in scale or map content or any other detail), as only a single map was used. The 1:50 000 map was altered to a scale of 1:20 000 to ensure that it was readable on the 19-inch light-emitting diode (LED) computer screen with a resolution of at least $1366 \times 768$ which was used in the experiment. The computers used for the experiment were standard issue Windows 7 65-bit lab computers with an i5 $3.1 \mathrm{GHz}$ central processing unit (CPU) and 4 gigabytes (GB) of random-access memory (RAM). 


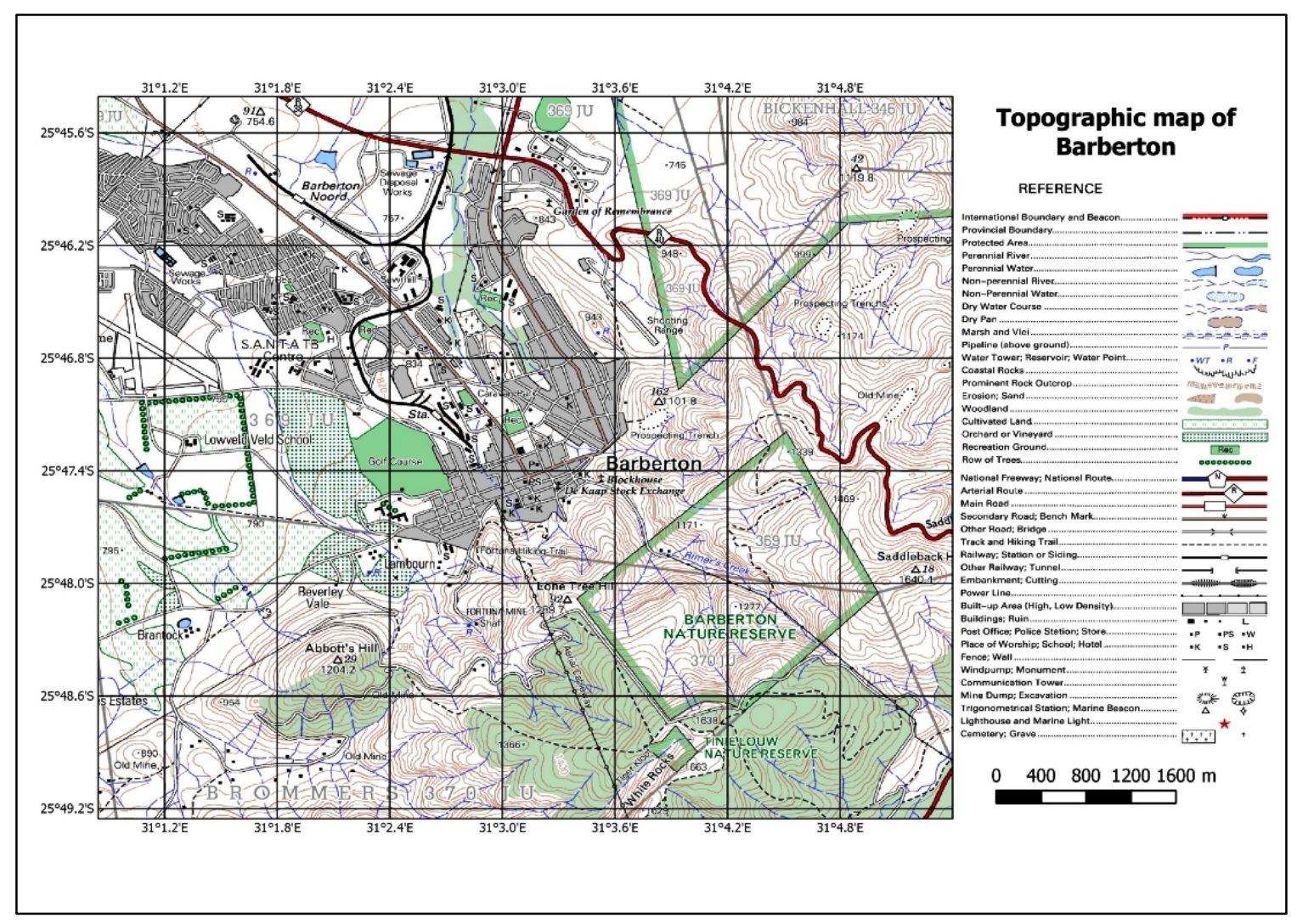

Figure 1. Topographic map of Barberton (Source CD:NGI 2009)

\subsection{Participants}

Forty-nine volunteers (24 males and 25 females) ranging from 18 to 42 years old (average age of 23) participated in the experiment. Approximately half of the participants were undergraduate students in geoinformatics $(51 \%)$ while others were students in related domains (a full breakdown of participants' occupation and degree programs is shown in Figure 2). Forty-five participants (92\%) indicated that they took geography at either high school or university level. Thus we assumed that they have a good foundation in map reading, specifically topographic maps, as it is taught already in high school geography in South Africa (Department of Basic Education, 2011; Department of Basic Education, 2012). The remaining four participants who indicated that they do not have any formal education in geography were undergraduate students in geoinformatics, who had already completed a number of geography and cartography courses at the university level. We thus deduced that all our participants were functionally map literate.

Thirty-six participants (73\%) were not familiar with Barberton and 13 participants (27\%) were familiar with the town (the level of familiarity was not specified; however, familiar and unfamiliar groups were separately analysed). It was important that the participants were not familiar with the Barberton area, as prior knowledge would have affected their overall performance in the experiment.

To establish the participants' overall experience in map reading and related tasks, they were asked to rate their training and experience on a five-point Likert scale. Their self-reported training and 
experience levels are shown in Figure 3. In general, all participants rated their experience or training in all aspects as average or above average ( 3 or higher). The only aspects that were rated lower than the average were training in cartography, training in computer graphics and training in planning. The lack of training in computer graphics and planning can be attributed to the fact that most participants were geoinformatics students who do not have to complete computer graphics and planning courses.

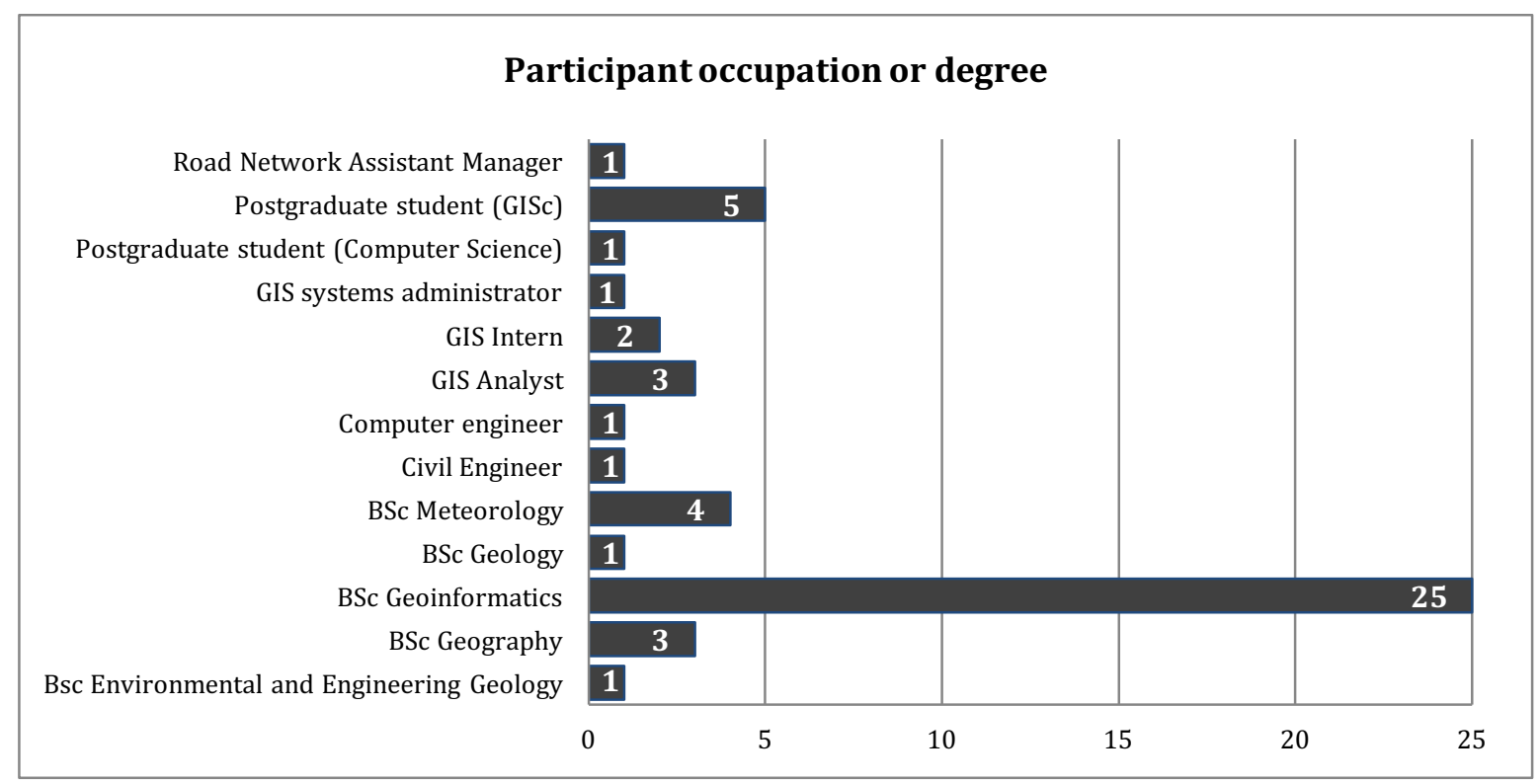

Figure 2. Degree or occupation of participants

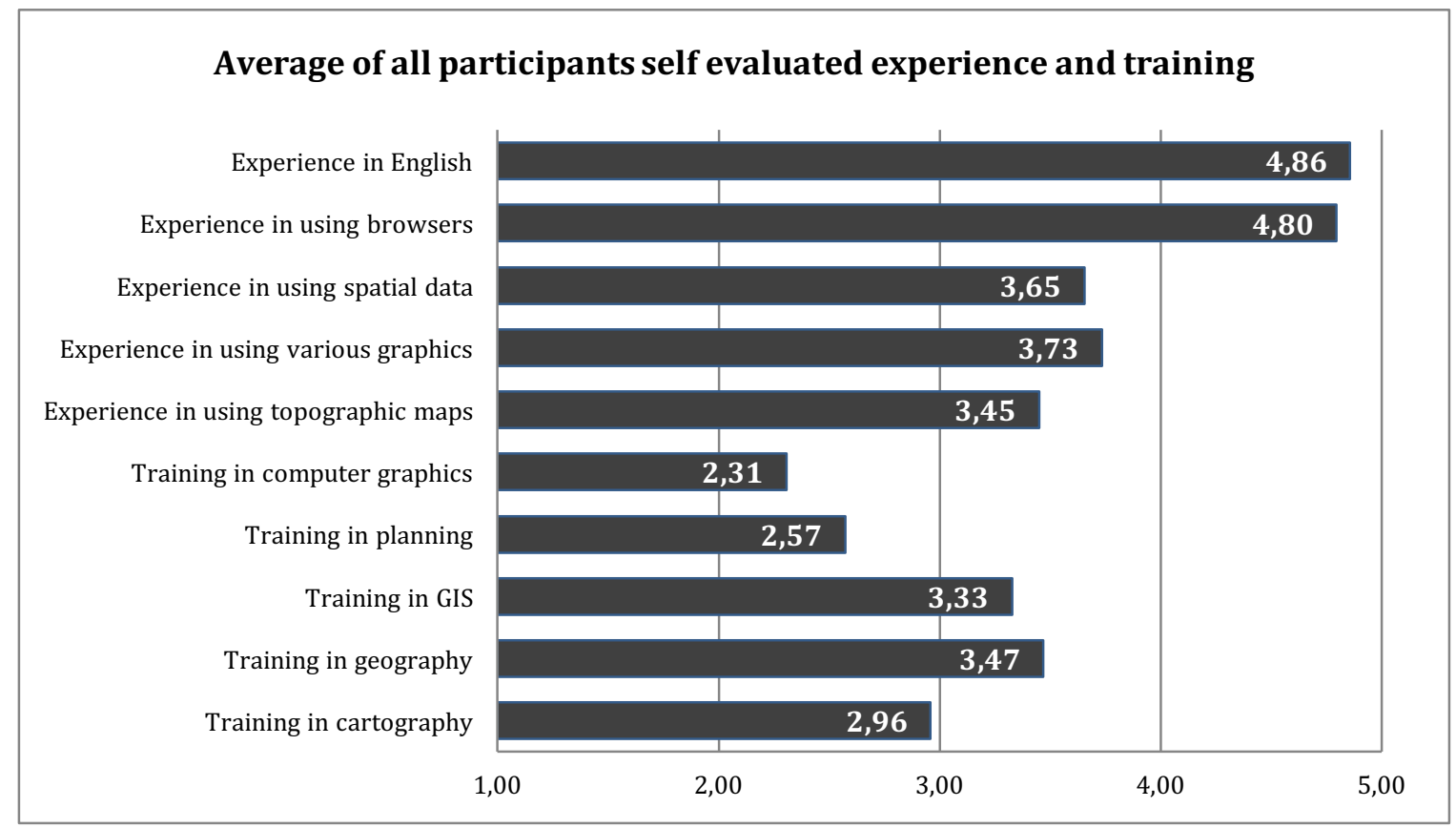

Figure 3. Participants' average self-reported experience and training 


\subsection{Procedure}

We conducted the experiment in the form of a questionnaire using an online survey software product, called Qualtrics, ${ }^{2}$ in a classroom (i.e., in a controlled environment). Groups of participants (approximately 20 participants in a lab with 40 computers) completed the survey using a web browser in a lab on computers connected to the Internet (see Section 3.2). Therefore, the processing power of the computers, the display sizes, keyboards as well as the bandwidth, were identical for all participants. Before the survey started, the instructor explained to the participants that they would be asked to complete various map reading tasks, and asked participants not to communicate with each other during the session. They were given no time limits. A technical assistant was available to provide support with any technical issues during the session (fortunately, there were no technical issues during the experiment). After the instructions, the participants responded to the questions, and when they completed the tasks, we thanked them and finished the session. The participation was voluntary, and we offered no compensation to the participants.

\section{Results}

In this section, we first present the results on whether and how the individual tasks (our independent variable) affected the participants' accuracy scores, their completion time and confidence (our three dependent variables). Then we present how task types connected to map literacy levels affected performance. The latter is based on our main hypothesis that participants' overall performance (accuracy and completion time) and confidence will vary as the levels are advanced, because all the participants are functionally map literate.

As mentioned earlier, the experiment consisted of 22 questions, and at least two of these questions were linked to a task type (thus associated literacy levels) as indicated in Table 1. A single outlier was removed; the participant only completed two of 22 questions. Based on the participants' accuracy (was the answer correct?), an accuracy score out of 100 was calculated for each participant. Accuracy scores were normally distributed, i.e., the skewness of the data is -0.771 (all skewness values between -1 and 1 are regarded as normal), and the kurtosis is 0.563 . The skewness results for the four accuracy scores in relation to the map literacy levels (referring to task taxonomy levels in Table 1) were slightly different: Level 1 (0.113), Level 2 (-1.891), Level 3 (-1.195) and Level 4 (-0.162). Level 2 and Level 3 indicate a negative skewness, meaning that participants did above average in these two levels.

First, we analysed the effect of familiarity (i.e. prior knowledge) with the area on the map reading tasks. We found that prior knowledge of the area had no effect on the accuracy score $[F(1,46)=$ $0.010, p=.922]$, confidence $[F(1,46)=0.055, p=.816]$ and task completion time $[F(1,44)=3.694, p$ $=.061]$. In other words, the participants who self-reported 'familiar' with the town did not overall

\footnotetext{
2 http://www.qualtrics.com
} 
perform better, suggesting perhaps the level of familiarity was not very high. Thus we kept their data along with the others in all analyses.

\subsection{Participant performance and confidence per question (individual tasks)}

Figure 4 provides an overview of the relationship between the participants' average accuracy scores (in percentage), and their average question completion time (in seconds) to complete each individual question. A strong negative correlation (Pearson correlation $=-0.732, p=.000$ 2-sided) between the average accuracy score and the average question completion time was observed. This shows that the participants made more mistakes with the harder questions and they took longer to complete the task - in other words, we did not observe a speed-accuracy trade-off.

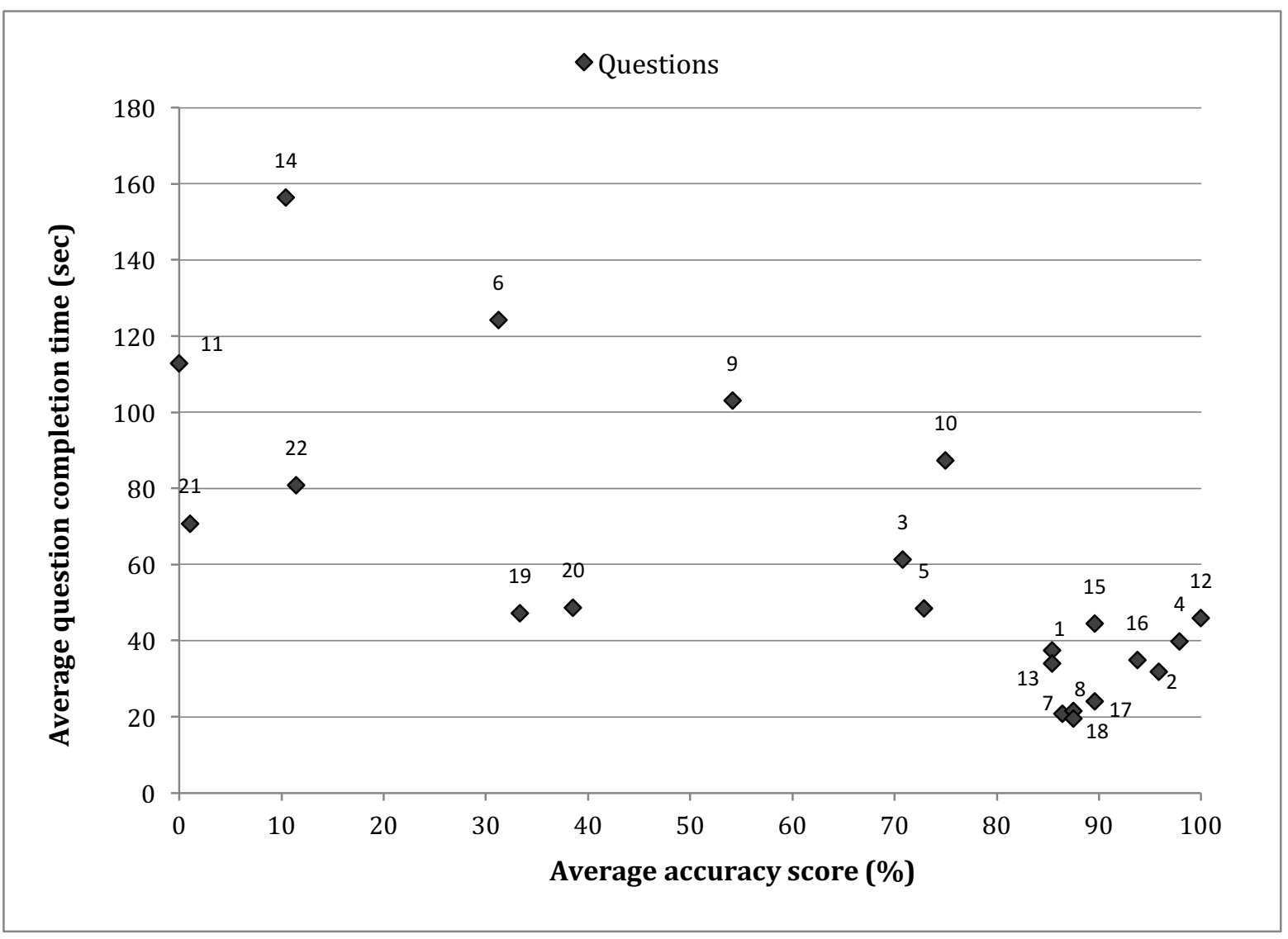

Figure 4. The average accuracy score in percentage compared to the average question completion time

Besides the accuracy and question completion time, we analysed how the confidence levels changed over all tasks. As can be seen in Figure 5 participants indicated relatively high levels of confidence for all questions (between $59 \%$ and $93 \%$ ).

Considering that the questions were designed to vary from simple to complex as we go from 1 to 22 , in Figure 5, we see that on average, the levels of confidence is matching with the levels of difficulty. 
With questions 21 and 22 (determine the area or extent of a region), participants marked their confidence level the lowest. In these two questions, and question 11 and 14 (specifying a location using coordinates), participants' accuracy scores were also the lowest. Despite the matching trend, the average confidence of the participants was skewed negatively (-1.295), supporting the observation that participants were over-confident on average (they over-estimated their performance). A two-tailed Spearman's rho test was used to analyse the correlation between the average accuracy score and confidence of participants. We observed a significant correlation between the accuracy score and confidence (Spearman's rho $=0.225 p=.028$ 2-sided), suggesting that participants were aware of their relative task performance (i.e., they were somewhat able to judge when they did not do too well, despite a general trend of over-confidence).

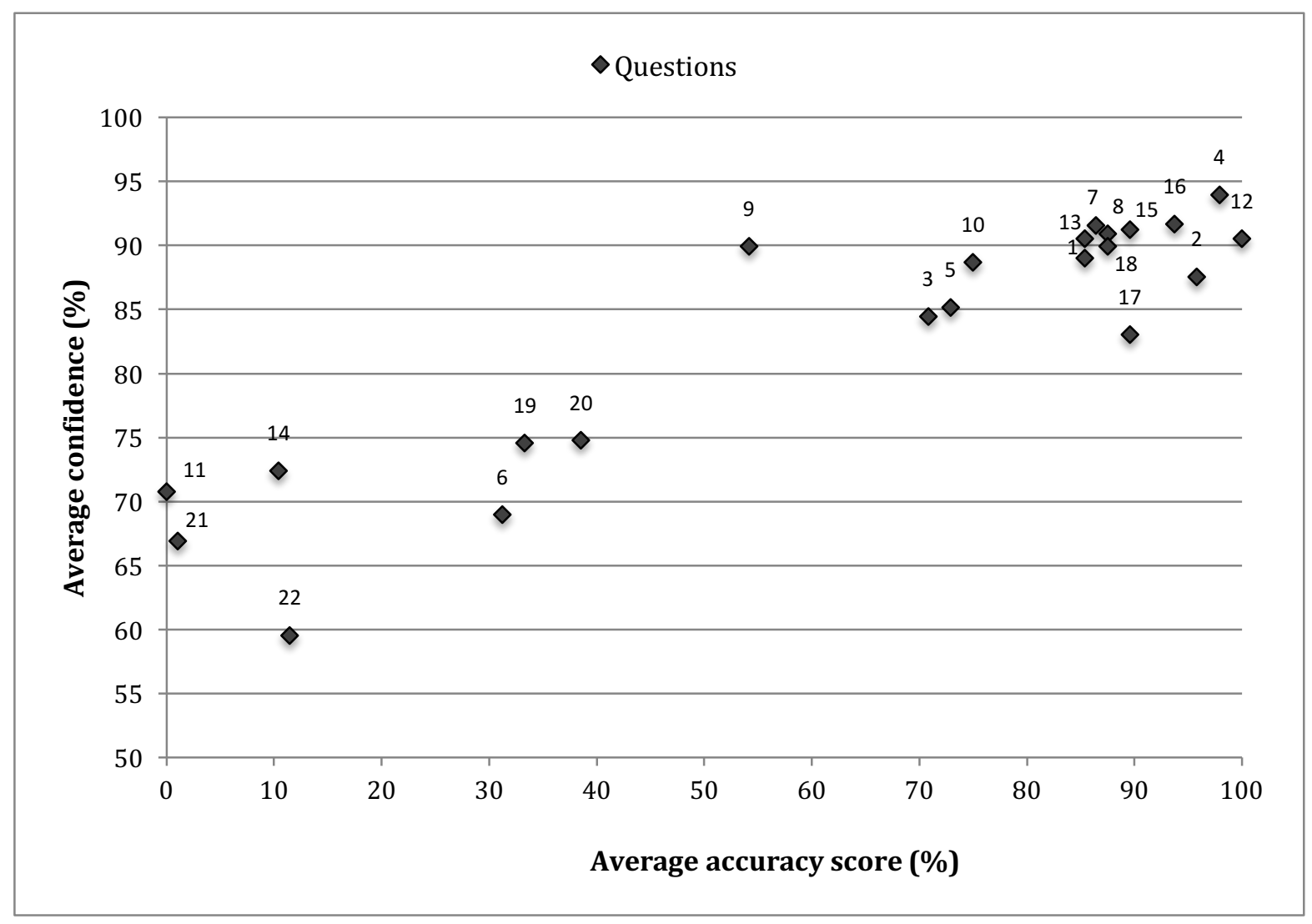

Figure 5. The average accuracy score in percentage compared to the participant's confidence for each question

\subsection{Participant performance and confidence per task type in relation to map literacy levels}

At this point, to verify the patterns at the task level, we aggregated the individual questions into task types as presented in Table 2, and studied the relationship between the accuracy scores and task completion time (response time) again, at an aggregate level. Figure 6 shows that a similar pattern (as in Figure 4) emerges as we compare the average accuracy score and task completion times (as 
specified in Table 2, a task may be represented by two or more questions) and verifies our observations at the question level. Furthermore, we did not observe a statistical correlation between the accuracy scores and task completion time per task type, suggesting that there was no speedaccuracy trade-off at the task type level either.

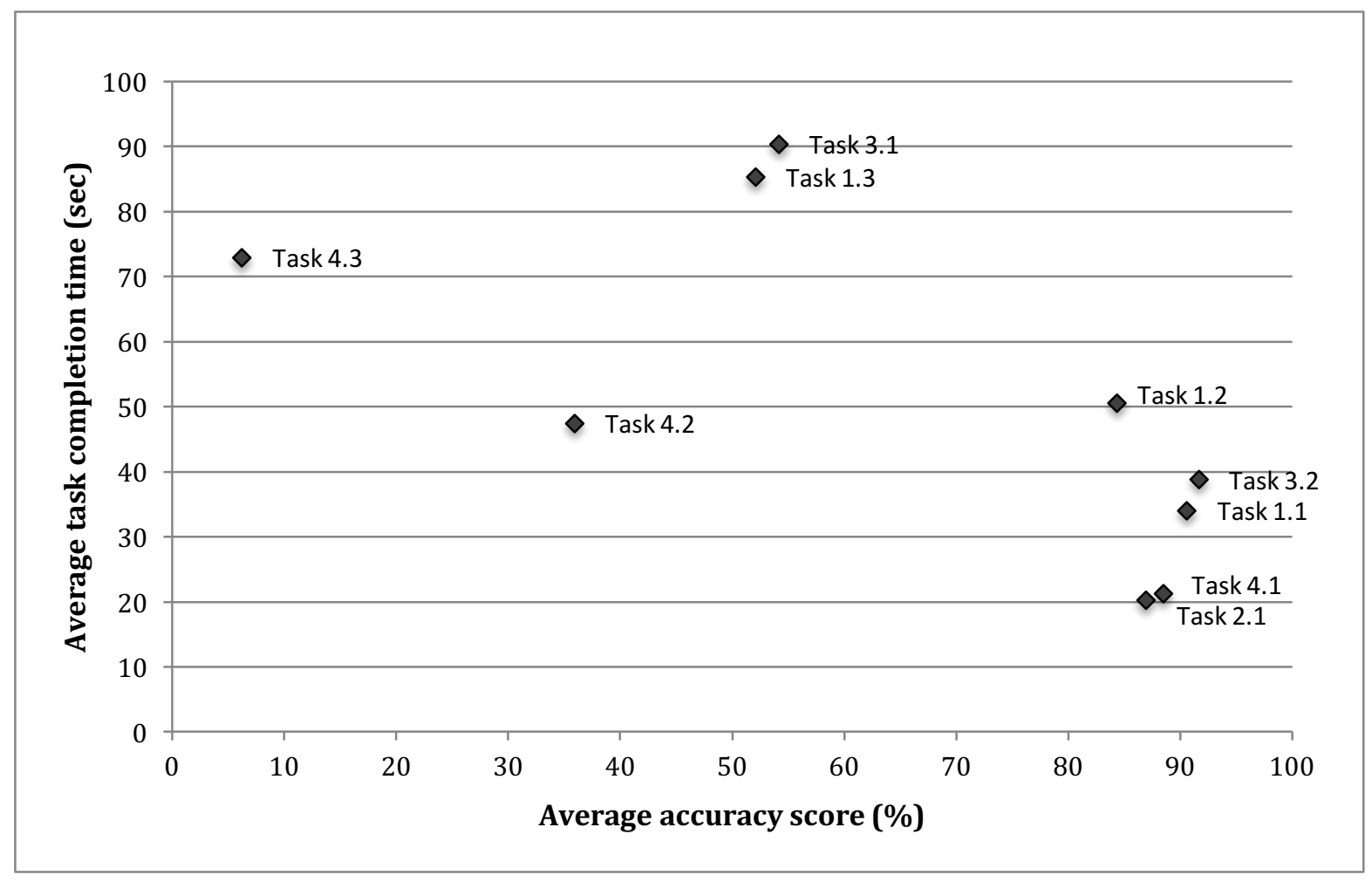

Figure 6. The average accuracy score in percentage compared to the average task completion time for each task (as specified in Table 2)

\subsection{Participant performance and confidence per map literacy level}

We expected that all participants would attain high accuracy scores, as they are trained in map reading through their educational attainments and self-reported experience levels (see Figures 2 and 3), i.e., our participants are a map literate sample. However, as mentioned earlier, we also expected the accuracy scores to decrease as the tasks associated with higher levels of literacy were presented, because the higher levels contain presumably harder tasks (as specified in Table 1).

Accuracy scores in relation to the map literacy levels can be seen in Figure 7. The participants achieved a lower accuracy score in Level 1 (75.69\%) compared to Level $2(86.98 \%)$, which was an unexpected result. We believe this is mostly explained by the low success rates with Task 1.3, specifically in question 6 (Indicate the lowest point shown in the map) participants performed below expectations (see Figure 7 ): only $20.4 \%$ of the participants were able to find the lowest elevation point on the map. This result can possibly be attributed to the fact that individuals might find it difficult to read and understand contour lines, as suggested by Chang et al. (1985). 


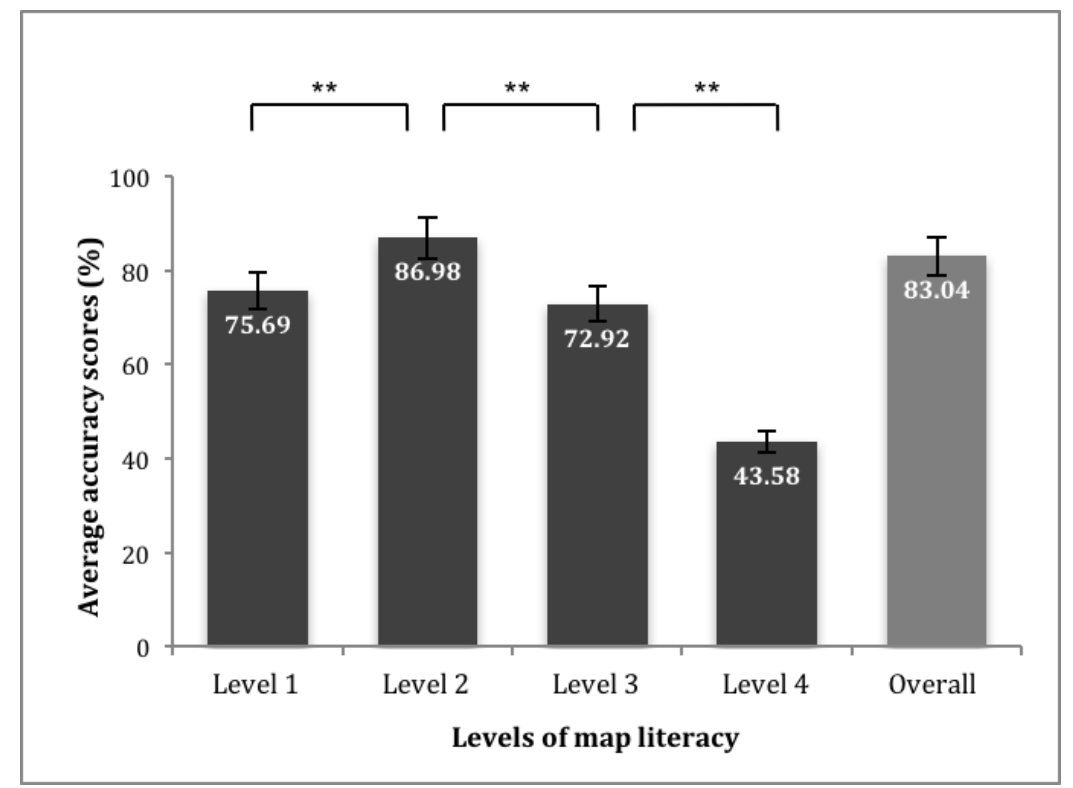

Figure 7. The average accuracy scores for each of the map literacy levels for all participants.

Error bars: +-SEM. ${ }^{* *} \mathrm{p}<0.01$

A one-way ANOVA revealed that the accuracy score increased between Level 1 and Level 2, $\mathrm{t}(47)=$ $-2.9, p=.006$ (refer to Figure 7). The accuracy score then decreased from Level 2 to Level 3 as expected, $t(47)=3.208, p=.002$, and also between Level 3 and Level $4, t(47)=11.17, p=.00$.

To complete the performance analysis, after studying the accuracy (as shown in Figure 7), we analyzed the average task completion time per map literacy level, seen in Figure 8.

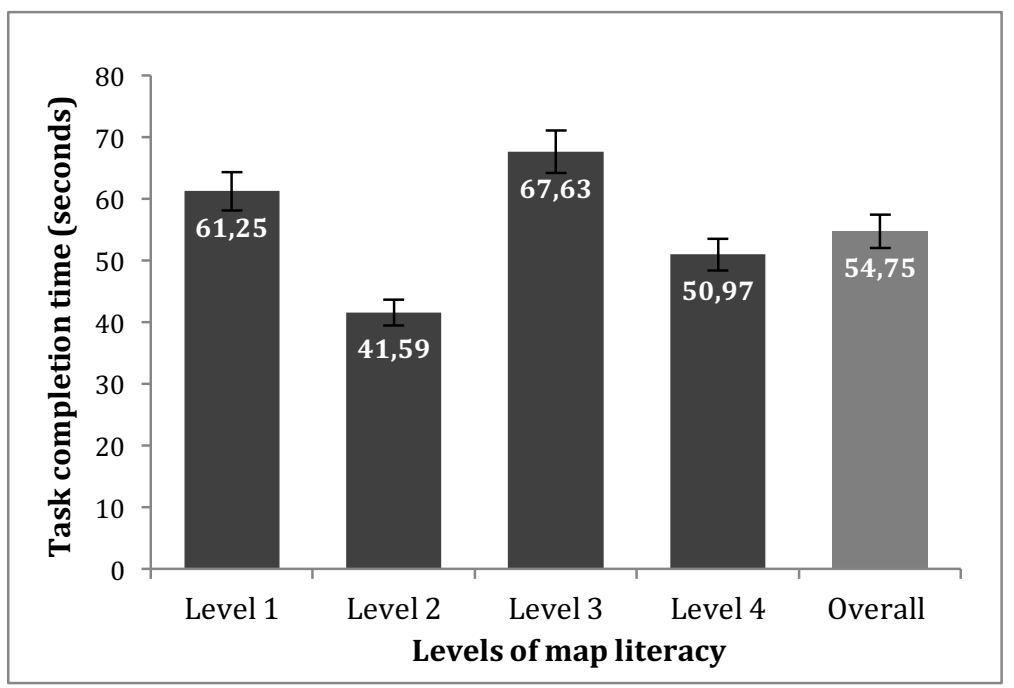

Figure 8. The average completion time for each of the map literacy levels for all participants.

$$
\text { Error bars: +-SEM }
$$

In Figure 8, we observe that generally participants took a small amount of time (between $\sim 40$ seconds and $\sim 70$ seconds) to complete the tasks. The correlation between the completion time per level and accuracy scores remains also at this aggregation level, especially when looking at Level 2. A one-way ANOVA was performed to analyse the effect of the different map literacy levels on the 
average completion time per map literacy level, [Level $1, F(6,39)=1.77, p=.129$, Level $2, F(3,42)=$ 0.297, $p=.827$, Level 3, $F(8,37)=1.643, p=.146$ and Level $4, F(7,38)=1.194, p=.33$ ]. The results revealed that the different levels had no statistical effect on the average time taken to complete tasks for each map literacy level.

Furthermore, to understand if the participants' confidence would reflect the task complexity, we analysed the confidence levels in relation to tasks per map literacy level (Figure 9).

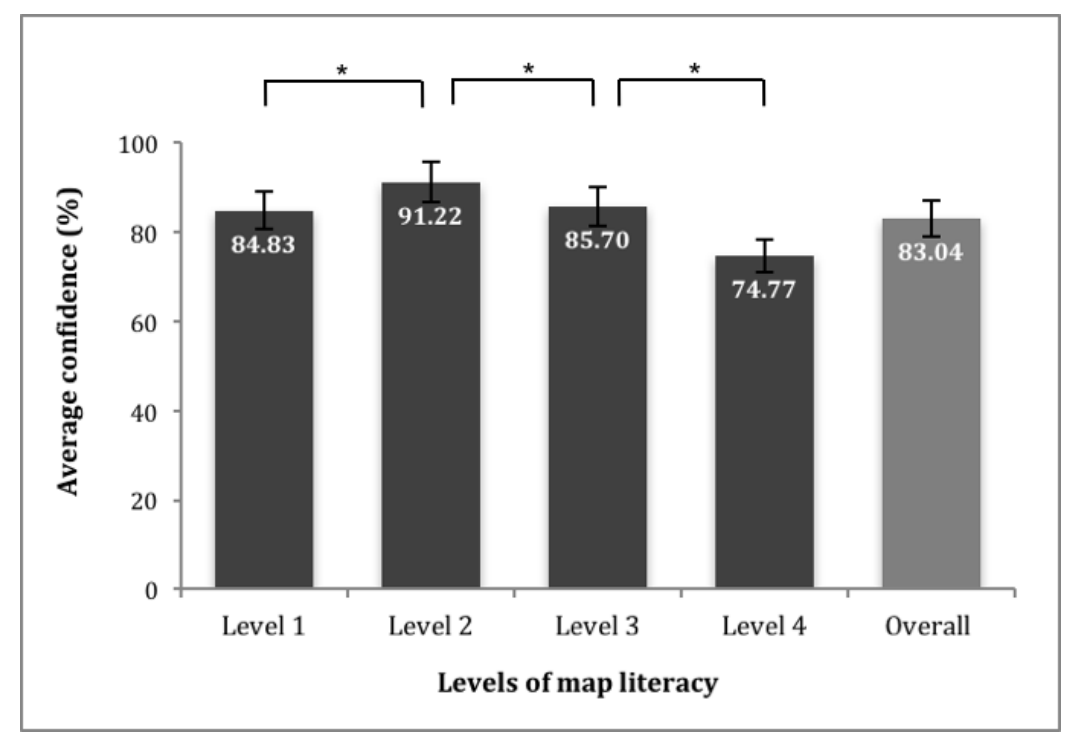

Figure 9. The average confidence for each of the map literacy levels for all participants. Error bars: +-SEM. * $p<0.05$

Figure 9 shows the average confidence of participants for each level. Again we can see that participants were very confident in their answers, with a slight decrease at Level 4, which consisted the most challenging questions and the participants possibly detected this. The participants' average confidence increased between Level 1 and Level 2, $t(47)=-2.37, p=.022$, and then slightly decreased between Level 2 and Level $3, t(47)=2.21, p=.032$ and also decreased to Level $4, t(47)$ $=2.414, \mathrm{p}=.020$.

\subsection{Exploratory group differences in performance and confidence based on experience and gender}

To better understand if the results vary based on participant characteristics, we studied the effect of experience and gender. Note that the study was not fully counterbalanced (i.e., we did not control for the number of experts among men or women, etc.). However, we present an exploratory analysis here, as previous literature suggests that performance differences might be related to experience levels, and confidence sometimes depends on gender (Biland and Coltekin, 2016). Experienced participants were defined as participants who rated themselves as 'excellent' in all categories of the self-reported familiarity and experience questionnaire. This resulted in 16 experienced ( 8 males and 8 females) and 32 inexperienced participants (16 males and 16 females). 
There was a slight difference between the experienced and inexperienced participants in terms of accuracy scores for each literacy level (see Figure 10). However, a one-way ANOVA revealed that this difference was not statistically significant, $F(1,46)=0.413, p=.524$. Additionally, no statistically significant correlation was found between the participants' experience and their performance for each task.

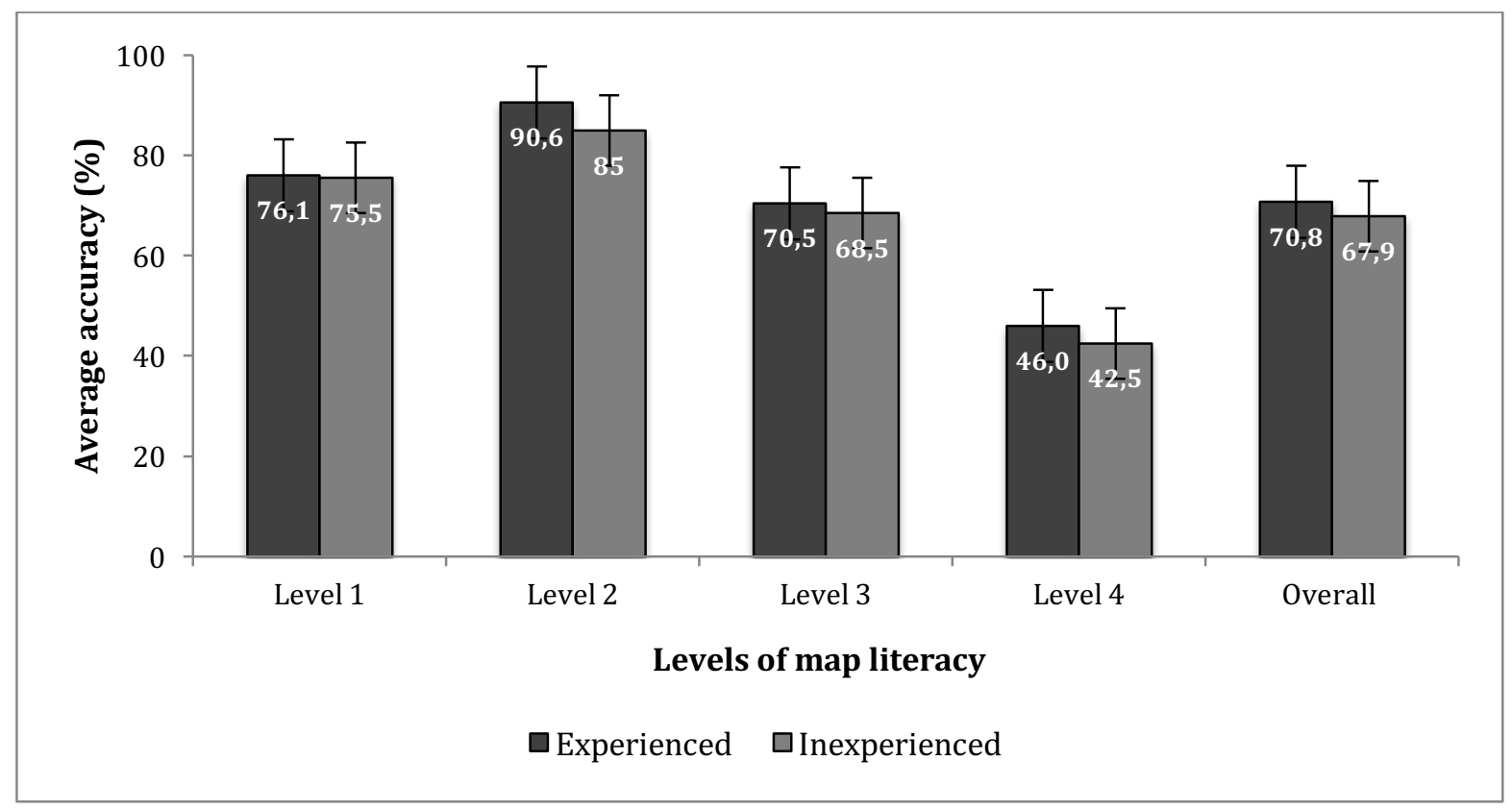

Figure 10. The average accuracy scores in percentage of the experienced and inexperienced participants for each literacy level. Error bars: +-SEM

Experienced participants took more time to complete the questions in comparison to the inexperienced participants. A one-way ANOVA revealed that this difference was statistically significant, $F(1,44)=6.540, p=.014$. The experienced participants generally also rated their confidence higher than inexperienced participants, this difference was found to be statistically significant, $F(1,46)=6.677, p=.013$.

In terms of gender differences, women achieved a slightly higher accuracy than men (Figure 11), however a one-way ANOVA revealed that this difference was not statistically significant $F(1,46)=$ $2.424, p=.126$. Similarly as the experts, women also took more time than men to complete the task. However, this was found to not be statistically significant, $F(1,44)=0.428, p=.516$. We found that gender had no effect on confidence $[F(1,46)=0.091, p=.764]$ and task completion time $[F(1,46)=$ $0.424, p=.126]$. 


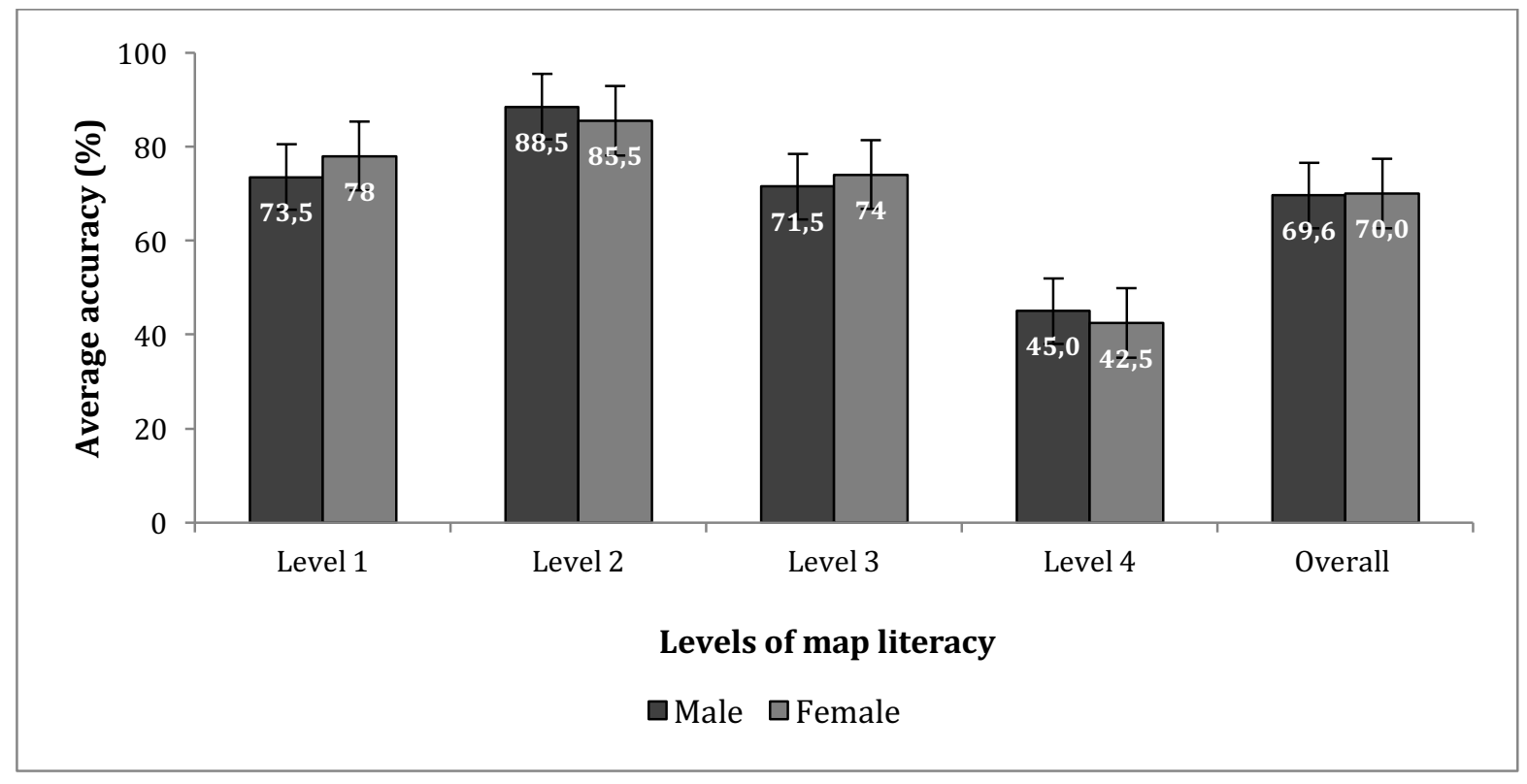

Figure 11. The average accuracy score in percentage of males and females for each task.

Error bars: +-SEM

\section{Discussion and conclusion}

In this paper, we first presented a map reading task taxonomy that we specifically designed for spatial planning based on the literature, reports, policies, and information we obtained through qualitative consulting with expert spatial planners. Our overarching goal was to identify geographic visualization (map) types that are helpful and functional for specific spatial planning tasks (or task types) when the levels of map literacy vary, and explain why these visualizations are fit for the given context and the audience. The specific goal of this paper was to investigate whether our proposed taxonomy indeed 'works as expected' in terms of our classification of map literacy levels. To achieve this, we designed a user experiment for a subset of the proposed map reading taxonomy (Levels 14), and tested it with a group of 49 functionally map literate participants using a topographic map. We found that the proposed tasks yield results broadly as expected, thus provide a good reference for evaluating topographic map literacy levels.

The results showed that participants' accuracy scores were overall very high in all questions relating to the first two levels (Level 1 and Level 2). It seems that the symbols on a topographic map are generally easy to identify when provided with a comprehensive legend: i.e., the average accuracy on questions 1 to 4 (Level 1 ) was above $70 \%$. The complexity of tasks in the proposed taxonomy increases from Level 1 to Level 4 , and we therefore expected the accuracy scores to decrease from Level 1 to Level 4. This was true for Level 2 to Level 4, but the participants surprisingly performed better in Level 2 compared to Level 1 (discussed below). The average accuracy scores of participants dropped from above $70 \%$ to below $50 \%$ from Level 3 to Level 4 . 
Four of the map reading tasks were particularly challenging for our participants: 1) Recognise various topographic features in the area based on symbology or patterns (Task 1.3); 2) Determine the position at a specific point (Task 3.2); 3) Determine the distance between two points or length of a linear feature (4.2); and 4) Determine the area or extent of a region (Task 4.3). The average confidence of the participants for these tasks was also lower than for the other tasks.

The unexpected increase in the average accuracy score from Level 1 to Level 2 appears to be mainly due to the poor performance in question 6 (Task 1.3 ). Only $20.4 \%$ of participants correctly indicated the lowest point on the topographic map (question 6, Task 1.3). We believe this is explained mainly by the poor interpretation of the contour lines. Chang et al. (1985) suggested that the development of a 3D mental image of the terrain from contour lines is challenging for most individuals. The result for Task 1.3 supports this. The evaluation of the responses for the lowest point focused on recognizing the correct pattern in the contour lines and a response within an acceptable distance from the lowest point was also considered to be correct. Additionally, spot heights on the map were also printed quite small and the participants might have struggled to read the labels. To overcome this challenge, 3D geovisualizations could be considered as an alternative, shown side-by-side, or allow interactive change of perspective to oblique or street level viewing where possible. In some environments or terrains, 3D geovisualizations may simplify tasks relating to topography, such as identifying the lowest or highest point (Rautenbach et al., 2015; Schobesberger and Patterson, 2008; Popelka and Brychtova, 2013). The opposite question (question 5, Task 1.3) for indicating the highest point was easier, as there was a distinctive peak with a label on the map and $71.4 \%$ of the participants correctly identified "Saddleback peak" as the highest point on the map. The remaining $28.6 \%$ participants indicated one of the other peaks in the area as the highest (there were six peaks indicated on the entire the map). Note that, for the highest point, only "Saddleback peak" was accepted as the correct answer, as the six peaks were displayed with elevation values on the map.

Participants' accuracy with determining the position at a specific point (Task 3.2) was significantly lower in the questions requesting numeric coordinates (question 11 and 14), than in the question requesting an alphanumeric grid reference (question 10). Participants understandably struggled to accurately estimate the decimals for the minute in the coordinates.

The drastic decline in the average accuracy score from Level 3 to Level 4 can possibly be explained by the lack of tools, such as a calculator, during the experiment. The participants needed to use the scale bar and then calculate distance or area using multiplication. Most of the errors in Level 4 tasks were of an arithmetical nature and related to area calculations. Accuracy in length and distance estimations was higher, most likely because multiplying or dividing by 1,600 for length and distance estimates is simpler than multiplying, e.g. 230 with 60 , to calculate area. The type of errors observed for Level 4 tasks confirms that participants struggled with complex multiplications but understood the principle of scale, line-of-sight, and slope steepness. That is, participants were overall competent on Level 4. Therefore, despite the low average accuracy scores on the four tasks in this level, it can be 
said that all participants were competent on all four levels, i.e., the participants in our experiment are functionally map literate. We therefore we conclude that the experiment successfully determined the functional map literacy of participants as expected.

We observed a strong negative correlation between the average accuracy scores and task completion time. Furthermore, there is a correlation between performance and confidence: participants achieved higher accuracy scores and took less time to complete the questions with which they reported higher levels of confidence in their performance. We also observed that experienced participants (consisting of $50 \%$ females) and females (51\% of all participants) tended to take more time than their counterparts did, and slightly outperformed them. The assumption was that all participants were map literate, and confirming this, we found no statistically significant correlation between the self-rated experience of participants and their performance. Even though there was no statistically significance between self-rated experience and performance, it does correlate to other research from Furnham $(1999 ; 2001)$ and Lloyd and Bunch $(2005 ; 2008)$. The fact that the overall performance was high was expected, because the experiment included only basic tasks on Level 1 to Level 4, and we recruited map literate participants who had previous exposure to similar topographic map reading tasks, either at school or at university.

Results of the experiment reported in this paper suggest that our map reading task taxonomy is suitable for evaluating topographic map literacy of a group of map literate individuals. The proposed map reading task taxonomy was developed based on literature authored by scientists from many different countries. We thus argue that the taxonomy we proposed in this paper could be used as a generalizable reference task taxonomy for evaluating topographic map literacy also in other countries. However, the taxonomy has not yet been tested with participants from other countries using their local topographic maps. In this analysis, a participant with an average accuracy of $70 \%$ or above was considered as map literate because with a $70 \%$ score most tasks were completed successfully. This being said, map literacy should be considered to be a continuum, rather than discrete or Boolean values. This notion is supported by Lee and Bednarz (2012), who stated that individuals might perform well on certain tasks and fail on others.

We plan to repeat the experiment with participants who have no experience in cartography and geography. If we can demonstrate that the performance by map-illiterate individuals are consistently lower than the map literate ones in this study, we will be able to strengthen the evidence that we created a systematic task taxonomy for evaluating map literacy. Furthermore, because the task taxonomy is customized for spatial planning, we will conduct experiments with spatial planners and support the evaluation process also with interviews where the tasks cannot be tested with closeended "survey-type" questions. Last but not least, we plan to further refine the map reading task taxonomy and also consider additional spatial visualizations, such as 3D models. 


\section{References}

Australian Government (2005) Map Reading Guide: How to use Topographic Maps. Canberra, Australia: Geoscience Australia.

Bachmann, M. (2015) Exploring and Addressing Functional Map Illiteracy in Community College Students. Papers in Applied Geography. 1(3), 258-261. DOI:10.1080/23754931.2015.1014674.

Bayram, S. (2007) Naïve and Expert Geography Students' Perceptions on Digital Map Literacy. SIMILE: Studies In Media \& Information Literacy Education. 5(4), 1-11.

Biland, J., \& Çöltekin, A. (2016). An empirical assessment of the impact of the light direction on the relief inversion effect in shaded relief maps: NNW is better than NW. Cartography and Geographic Information Science (in press).

Board, C. (1981) Cartographic communication. In L. Guelke, ed. Maps in modern cartography, Cartographica Monograph. 42-78.

Board, C. (1978) Map Reading Tasks Appropriate in Experimental Studies in Cartographic Communication. Cartographica: The International Journal for Geographic Information and Geovisualization. 15(1), 1-12.

Board, C., Taylor, R.M. (1977) Perception and Maps: Human Factors in Map Design and Interpretation. Transactions of the Institute of British Geographers. 2(1), 19-36.

Bolstad, P. (2012) GIS Fundamentals: A First text on Geographic Information Systems. 4th ed. St. White Bear, MN: Eider Press.

Brychtova, A., \& Çöltekin, A. (2014). An empirical user study for measuring the influence of colour distance and font size in map reading using eye tracking. The Cartographic Journal, 51(4).

Brychtova, A., \& Çöltekin, A. (2015). Discriminating classes of sequential and qualitative colour schemes. International Journal of Cartography, 1(1), 62-78.

Brychtová, A., \& Çöltekin, A. (2016). The effect of spatial distance on the discriminability of colors in maps. Cartography and Geographic Information Science, 1-17.

Chang, K.-T., Antes, J., Lenzen, T. (1985) The Effect of Experience on Reading Topographic Relief Information: Analyses of Performance and Eye Movements. The Cartographic Journal. 22(December), 88-94.

Clarke, D. (2003) Are you functionally map literate. In 21th International Cartographic Conference. Durban, South Africa: International Cartographic Association, 10-16.

Clarke, D. (2007) Impact of map literacy on development planning in South Africa. PhD Thesis. University of Stellenbosch, South Africa.

Engel, B. (2004) Developing map use skills for planners and implementers of land reform in South Africa. GeoJournal. 60, 183-189.

Furnham, A. (2001) Self-estimates of intelligence: Culture and gender difference in self and other estimates of both general $(\mathrm{g})$ and multiple intelligences. Personality and Individual Differences. 31(8), 1381-1405.

Furnham, A., Fong, G., Martin, N. (1999) Sex and cross-cultural differences in the estimated multifaceted intelligence quotient score for self, parents and siblings. Personality and Individual Differences. 26(6), 1025-1034. 
Innes, L. (2005) Identifying spatial competence outcomes for South African Secondary Schools. In Proceedings of the 22nd ICA International Cartographic Conference. Coruña, Spain: International Cartographic Association.

Innes, L. (2003) Maths for Map Users. In 21th International Cartographic Conference. Durban, South Africa: International Cartographic Association, 727 - 738.

Innes, L.M. (1998) Learning to Read the South African 1:50 000 Topographic Map: The development of a self-instruction method. Master's dissertation. University of Witwatersrand.

Keates, J.S. (1996) Understanding Maps. London, United Kingdom: Longman.

Kent, R.S.G., Cheng, P.C.-H. (2008) Expertise in a Map Reading Task: The Role of Schemas in the Processing of Topographical Relief Information. In Proceedings of the Thirtieth Annual Conference of the Cognitive Science Society. 2298-2303.

Koç, H., Demìr, S. (2014) Developing Valid and Reliable Map Literacy Scale. Review of International Geographical Education Online, 4(2). Available online at http://www.rigeo.org/vol4no2/Number2Summer/RIGEO-V4-N2-3.pdf [accessed 21 April 2016].

Land Information New Zealand (2009) Map Reading Guide: How to use a topographic map. Canberra, Australia: Land Information New Zealand.

Lee, J., Bednarz, R. (2012) Components of Spatial Thinking: Evidence from a Spatial Thinking Ability Test. Journal of Geography. 111(1), 15-26, DOI:10.1080/00221341.2011.583262.

Lloyd, R.E., Bunch, R.L. (2008) Explaining Map-reading Performance Efficiency: Gender, Memory, and Geographic Information. Cartography and Geographic Information Science. 35(3), 171-202.

Lloyd, R.E., Bunch, R.L. (2005) Individual Differences in Map Reading Spatial Abilities Using Perceptual and Memory Processes. Cartography and Geographic Information Science. 32(1), 33-46.

Morrison, J.L. (1978) Towards a Functional Definition of the Science of Cartography with Emphasis on Map Reading. Cartography and Geographic Information Science. 5(2), 97-110.

National Geo-Spatial Information (2013) 1:50 000 Topographical Maps. [online]. Available from: http://www.ngi.gov.za/index.php/what-we-do/maps-and-geospatial-information/35-mapproducts/51-1-50-000-topographical-maps [Accessed February 14, 2016].

Ooms, K., De Maeyer, P., Dupont, L., Van Der Veken, N., Van de Weghe, N., Verplaetse, S. (2016) Education in cartography: what is the status of young people's map-reading skills?. Cartography and Geographic Information Science. 43:2, 134-153.

Ordnance Survey (2015) Is map reading a forgotten skill? Available online at https://www.ordnancesurvey.co.uk/blog/2015/08/is-map-reading-a-forgotten-skill/ [accessed 21 April 2016].

Ordnance Survey (1992) Map of Reading. Analytical Proceedings. 29(8), 383.

Ordnance Survey (2014) Map reading made easy peasy. Southampton, UK. Available online at https://www.ordnancesurvey.co.uk/docs/leaflets/map-reading-made-easy-peasy.pdf [accessed 21 April 2016].

Popelka, S., Brychtova, A. (2013) Eye-tracking Study on Different Perception of 2D and 3D Terrain Visualisation. The Cartographic Journal. 50(3), 240-246.

Rautenbach, V., Bevis, Y., Coetzee, S., Combrinck, C. (2015) Evaluating procedural modelling for 3D models of informal settlements in urban design activities. South African Journal of Science. 
111(11/12), 1-10.

Rautenbach, V., Coetzee, S., Coltekin, A. (2014) Towards evaluating the map literacy of planners in 2D maps and 3D models in South Africa. In AfricaGEO 2014 Conference Proceedings. 1-12.

Rayner, H. (1996) Improving map literacy: The application of Second Language instruction views and techniques. Master's dissertation. Wilfrid Laurier University.

Rinner, C., Ferber, S. (2005) The Effects of Map Reading Expertise and Map Type on Eye Movements in Map Comparison Tasks. In Spatial Information Theory: International Conference, COSIT 2005, Ellicottville, NY, USA, September 14-18.

Saku, J.C. (1990) The impact of teaching cartographic lexicon and of geographic experience on map use. Master's dissertation. Wilfrid Laurier University.

Schobesberger, D., Patterson, T. (2008) Evaluating the Effectiveness of 2D vs. 3D Trailhead Maps: A Map User Study Conducted at Zion National Park, United States. In 6th ICS Mountain Cartography Workshop. Switzerland, 201-205.

South African Department of Basic Education (2011) Curriculum and Assessment Policy Statement Grades 10-12 Geography. Cape Town, South Africa: department of Basic education.

South African Department of Basic Education (2012) Mind the Gap: Geography Study guide Grade 12. Pretoria, South Africa: department of Basic education.

South African Department of Education (2008) National Curriculum Statement Grades 10-12 (General) Learning Programme Guidelines. department of Education.

United States of America Department of the Army (2001) Map Reading and Land Navigation: Field Manual. 3rd-25.26 ed. Washington, D.C.: Department of the Army.

Wiegand, P. (2006) Learning and Teaching with Maps. New York, New York, USA: Routledge. 